\title{
AN ANALYSIS OF VEHICLE VIBRATION WITH UNCERTAIN SYSTEM PARAMETERS
}

The study proposes an application of fuzzy arithmetic for analysis of randomly excited structures with uncertain or inexact system parameters. The purpose of the paper is to investigate possibilities of a fuzzy technique in a vehicle dynamic analysis. The solution of the problem will be realised in MATLAB using the program CAR_FUZ.M with a special module INTLAB.

\section{Introduction}

Engineering models of carrying structures are inevitably based on idealization of reality. Therefore, various degrees of idealization will provide different results. Generally, each engineering model has to consist of three fundamental components coherent to each other $[1,8]$ :

- loading (harmonic, periodic, stochastic etc.),

- structural model (geometry, material properties etc.),

LOADING (time or frequency functions)

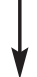

STRUCTURAL MODEL

(Mechanics + Mathematics + Numerics)

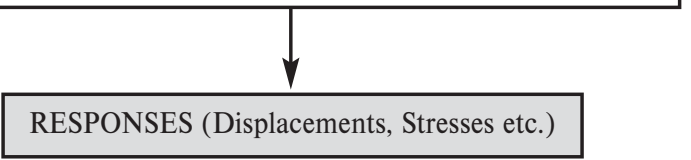

Fig. 1 Engineering models of structures

Uncertainty of each computational component (in loading or structural parameters) can be characterised by probability theory or fuzzy sets approach. Generally, uncertainties are often classified as imprecision, modelling and random [7]:

- imprecision is due to vagueness in a characterizing performance in terms such as "good" or "unacceptable"

- modelling uncertainty is due to reality idealization by the modeled structure and further simplifications in the computational models,

- random uncertainty reflects variations in the operating environment and lack of the designer control.

Several methods include safety factors, "worst-case scenario", probabilistic methods and fuzzy set based methods. This study
- response (displacements, accelerations, stresses, cumulative damage etc.).

focuses only on the treatment by fuzzy uncertainties, using fuzzy set theory and numerical analysis.

Fuzzy set based methods use possibility distributions to model uncertainties and assess safety. The possibility distributions are estimated using numerical data or expert opinion. In theory, probabilistic methods should be more effective for problems involving only random uncertainties, because they account for more information about these uncertainties than the other methods. However, to be applied, probabilistic methods may require more information than is available. On the other hand, fuzzy techniques require less data than probabilistic methods [1,2].

The theory of fuzzy sets was formulated by Zadeh [9]. A fuzzy set $x$ is the set with boundaries that are not sharply defined. A function, called membership function (MSF), signifies the degree to which each member of a domain $X$ belongs to the fuzzy set $x$ [11]. For a fuzzy variable $x \in\langle x 1, x 2\rangle$, (or $x \in \boldsymbol{x}$ ), the membership function is defined as $\mu(x)$. If $\mu(x)=1, x$ is definitely a member of the $x[5,6,11]$. If $\mu(x)=0, x$ is definitely not a member of the $x$. For every x with $0<\mu(x)<1$, the membership is not certain. Typical membership functions of fuzzy sets are shown in figures 1 and 2.

By fuzzy technique, the complete information about the uncertainties in the model can be included and one can demonstrate how these uncertainties are processed through the calculation procedure in MATLAB [1, 2].

$$
\mu_{A}(x)=\left\{\begin{aligned}
0, & x<a_{1} \\
\frac{x-a_{1}}{a_{2}+a_{1}}, & a_{1} \leq x \leq a_{2} \\
1, & x=a_{2} \\
\frac{a_{3}-x}{a_{3}-a_{2},} & a_{2} \leq x \leq a_{3} \\
0, & x>a_{3}
\end{aligned}\right.
$$

\section{* Milan Sága, Milan Letrich, Roman Kocúr}

Faculty of Mechanical Engineering, Department of Applied Mechanics, University of Žilina, Univerzitná 1, 01026 Žilina, Slovakia, E-mail: Milan.Saga@fstroj.utc.sk 


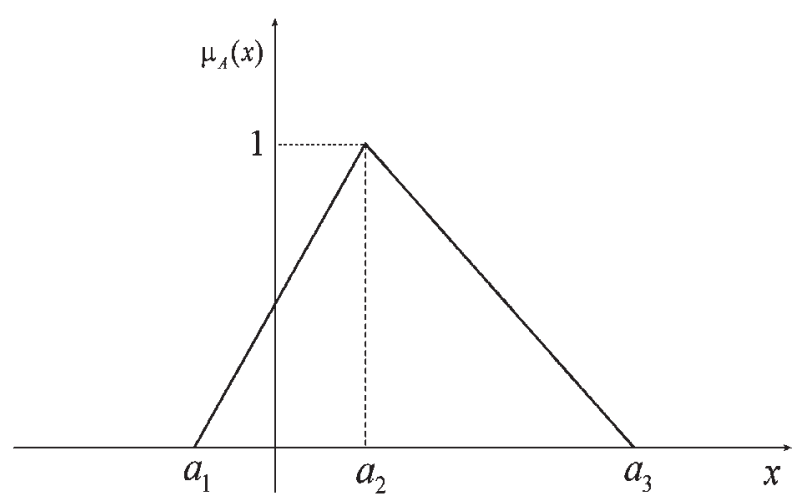

Fig. 2 MSF for a triangular fuzzy number

$\mu_{A}(x)=\left\{\begin{aligned} 0, & x<b_{1} \\ \frac{x-b_{1}}{b_{2}+b_{1},} & b_{1} \leq x \leq b_{2} \\ 1, & b_{2} \leq x \leq b_{3} \\ \frac{b_{4}-x}{b_{4}-b_{3},} & b_{3} \leq x \leq b_{4} \\ 0, & x>b_{4}\end{aligned}\right.$

\section{Numerical study of random vibration of a fuzzy vehicle computational model}

Vehicle dynamic models are often characterized by uncertain system parameters. A main goal of this example will be to analyse the influence of "uncertain" mass, damping, stiffness parameters to structural response and the mark of ride quality in a chosen point. The input will be expressed by a fuzzy random function (fuzzy function of the behaviour power spectral density).

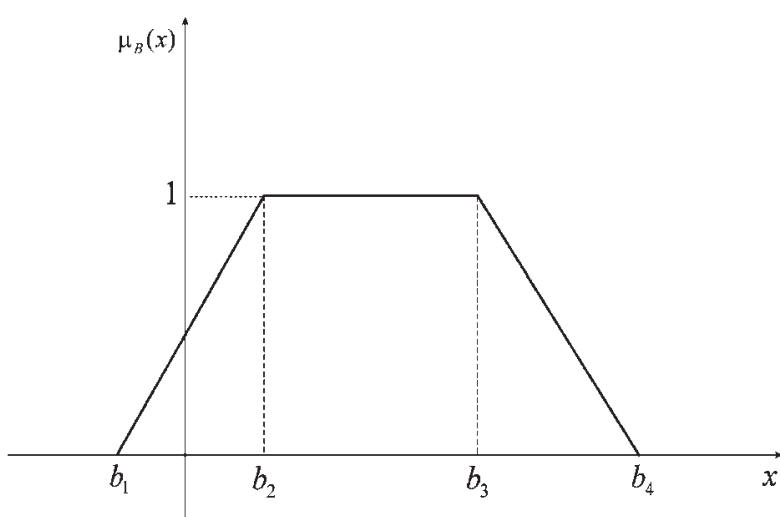

Fig. 3 MSF for a trapezoidal fuzzy number

Let's consider a 7-DOFs railway vehicle model (Fig. 4). The geometry of the model is following: $L=24.5 \mathrm{~m}, a_{1}=12 \mathrm{~m}$, $a_{2}=12.5 \mathrm{~m}, c_{1}=c_{2}=1 \mathrm{~m}$, coordinates of the point A: $x_{A}=13.5 \mathrm{~m}$, $z_{A}=1.1 \mathrm{~m}$. The vehicle speed will be $v=80 \mathrm{~km} / \mathrm{h}$. Other vehicle parameters will be:

- mass of the body of coach $\quad m_{1}=16100$ $[\mathrm{kg}]$

- moment of inertia with respect to the axis $z$

$J_{z 1}=787570 \quad\left[\mathrm{~kg} \cdot \mathrm{m}^{2}\right]$,

- moment of inertia with respect to the axis $x$

- mass of the bogie

$J_{x 1}=13700 \quad\left[\mathrm{~kg} \cdot \mathrm{m}^{2}\right]$,

- moment of inertia with respect to the axis $x$

- stiffness of primary springing

- stiffness of secondary springing

- damping coefficient of primary springing

- damping coefficient of secondary springing $m_{2}=3050 \quad[\mathrm{~kg}]$,

$J_{x 2}=1230 \quad\left[\mathrm{~kg} \cdot \mathrm{m}^{2}\right]$,

$k_{2}=360000 \quad[\mathrm{~N} / \mathrm{m}]$,

$k_{1}=200000 \quad[\mathrm{~N} / \mathrm{m}]$,

$b_{2}=20000 \quad[\mathrm{~N} . \mathrm{s} / \mathrm{m}]$,

$b_{1}=10000 \quad[\mathrm{~N} . \mathrm{s} / \mathrm{m}]$.
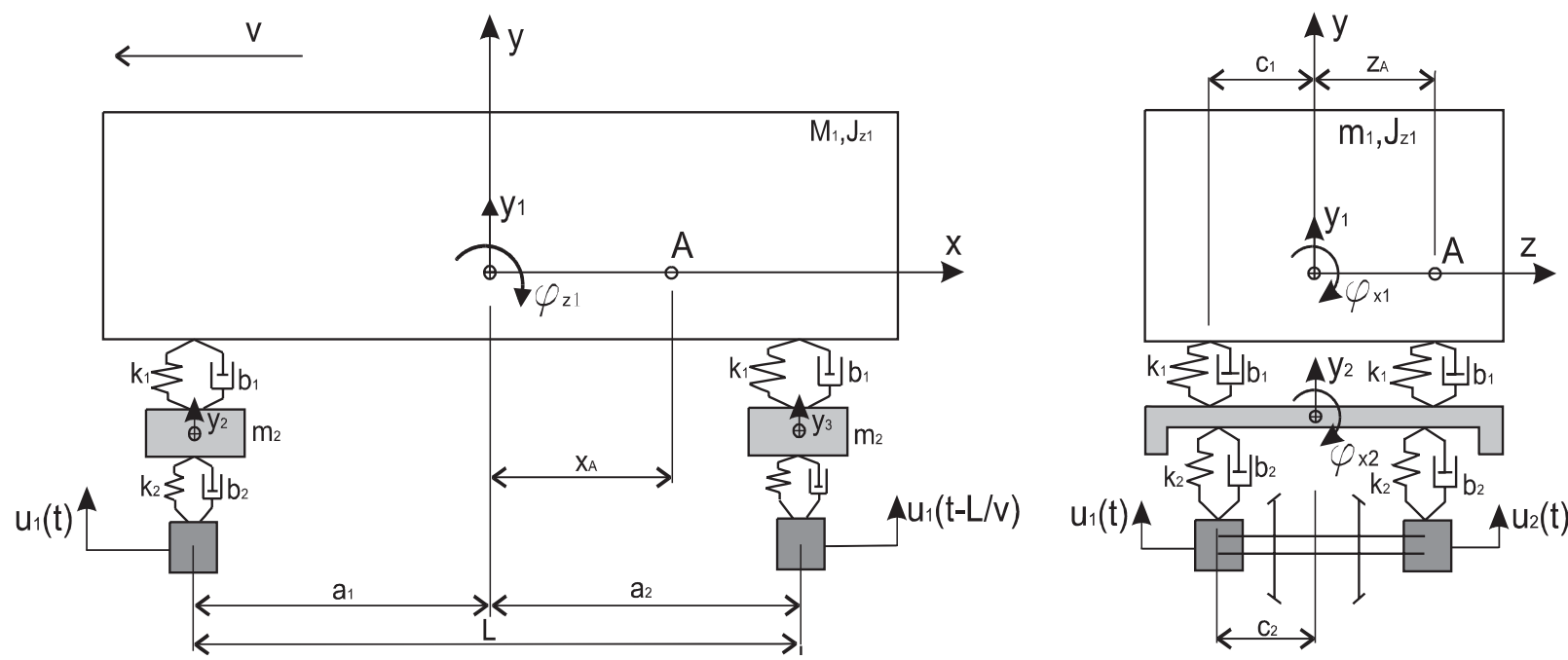

Fig. 4 Dynamic model of the railway vehicle 

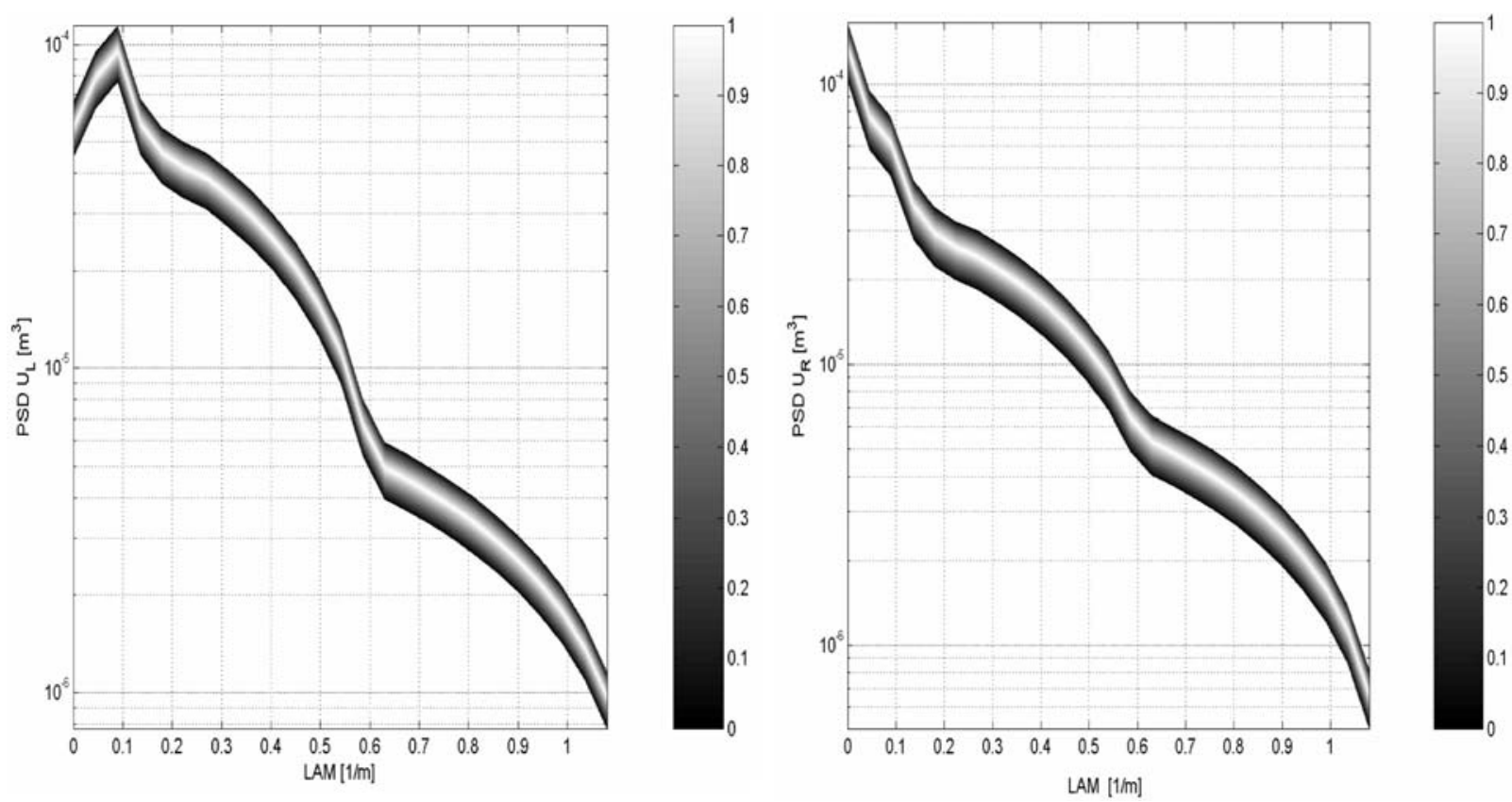

Fig. 5 Fuzzy PSD of the vertical track irregularities-left and right rail $\left(u_{1}=u_{L}, u_{2}=u_{R}\right), L A M=$ spatial frequency $[\mathrm{l} / \mathrm{m}]$

The following assumptions were employed to derive this model:

- The inputs of the system are two track undulations in the vertical direction.

- The unevenness of the track at the left rail and at the right rail are presented in Fig. 5 by using the power spectral density [3]. The motion of the wheels is restricted to the vertical direction only.

It is assumed that the model is linearized around the operating state and that the coordinates

$$
\boldsymbol{y}=\left[y_{1}, \varphi_{z 1}, \varphi_{x 1}, y_{2}, \varphi_{x 2}, y_{3}, \varphi_{x 3}\right]^{T}
$$

are measured from the equilibrium state. The equations of motion will be interpreted as follows

$$
M \cdot \ddot{y}+B \cdot \dot{y}+K \cdot y=T_{b} \cdot u+T_{k} \cdot u
$$

Matrices $M, B, K, T_{b}, T_{k}$ are presented in Appendix. Fuzzification of the structural parameters has been realised by multiplication of matrices $M, B, K$ by the fuzzy number $x$ presented in Fig. 6.

Applying the fundamental principles of correlation theory we can solve the equations of motion in the frequency domain using the known input fuzzy power spectral density (Fig. 5) as follows [4]

$$
S_{y y}(\omega)=H(i \omega) \cdot \boldsymbol{T}(i \omega) \cdot\left[\begin{array}{cc}
S_{u 1 u 1}(\omega) & 0 \\
0 & S_{u 2 u 2}(\omega)
\end{array}\right]
$$$$
\cdot \boldsymbol{T}^{T}(-i \omega) \cdot \boldsymbol{H}^{T}(-i \omega)
$$

where $\boldsymbol{H}(i \omega)=\left(-\omega^{2} \cdot \boldsymbol{x} \cdot \boldsymbol{M}+i \cdot \omega \cdot \boldsymbol{x} \cdot \boldsymbol{B}+\boldsymbol{x} \cdot \boldsymbol{K}\right)^{-1}$ and
$\boldsymbol{T}(i \omega)=\left(i \cdot \omega \cdot \boldsymbol{T}_{b}+\boldsymbol{T}_{k}\right) \cdot\left[\begin{array}{cc}1 & 0 \\ 0 & 1 \\ e^{(-i \cdot \omega \cdot L / v)} & 0 \\ 0 & e^{(-i \cdot \omega \cdot L / v)}\end{array}\right]$.

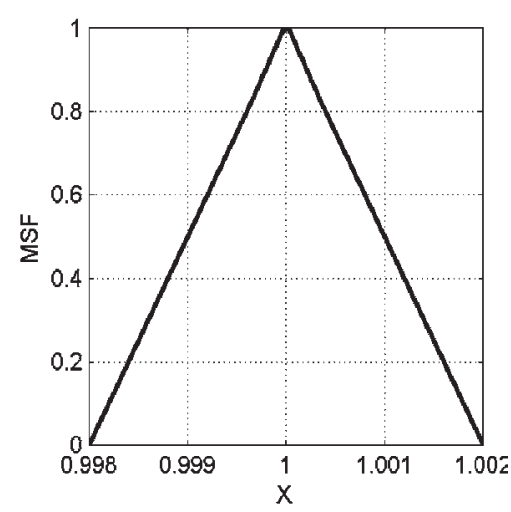

Fig. 6 Fuzzy number $x$

The fuzzy PSD function of the vertical motion of the point $A$ is

$$
\begin{aligned}
& S_{A}(\omega)=\left[\begin{array}{lllllll}
1 & -x_{A} & -z_{A} & 0 & 0 & 0 & 0
\end{array}\right] \\
& \cdot S_{y y}(\omega) \cdot\left[\begin{array}{lllllll}
1 & -x_{A} & -z_{A} & 0 & 0 & 0 & 0
\end{array}\right]^{T}
\end{aligned}
$$

and the mark of ride quality [4] will be

$$
W_{A}=3.33 \cdot\left(\frac{1}{2 \pi} \cdot \int_{0}^{\omega_{\max }} \omega^{4} \cdot S_{A}(\omega) \cdot d \omega\right)^{1 / 6} .
$$

By using the results, it is possible to study the influence of the accumulation of uncertain vehicle parameters. For this purpose, 


\section{kaM Nikocle}

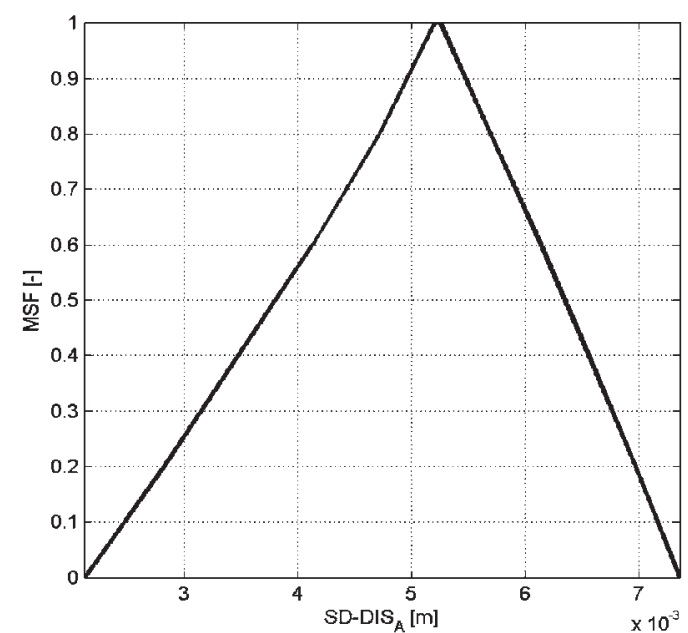

Fig. 7 Fuzzy standard deviation of the vertical displacement of

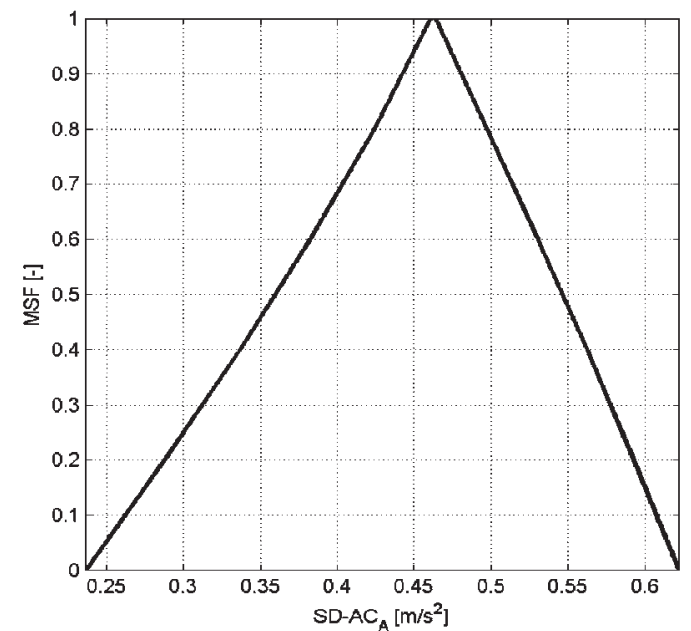

Fig. 9 Fuzzy standard deviation of the vertical acceleration of point

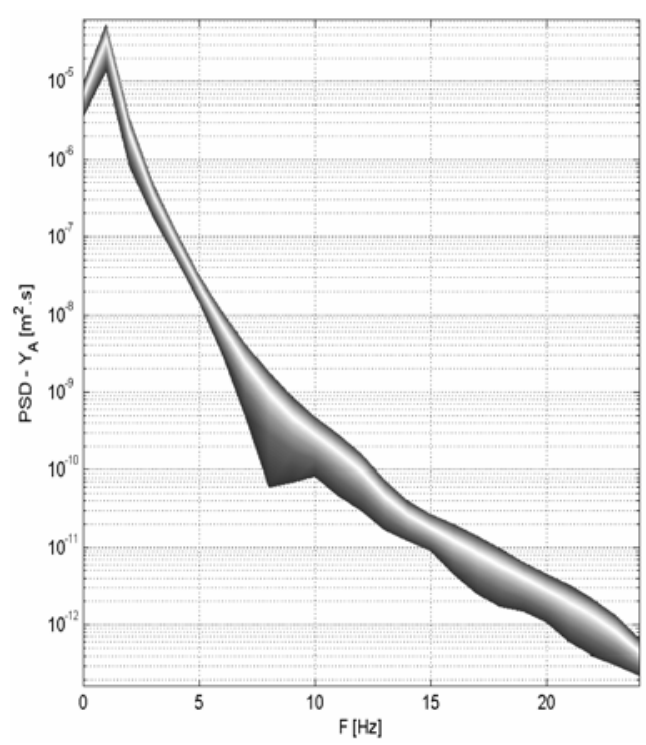

Fig. 11 Fuzzy PSD of the vertical dispavement of point A

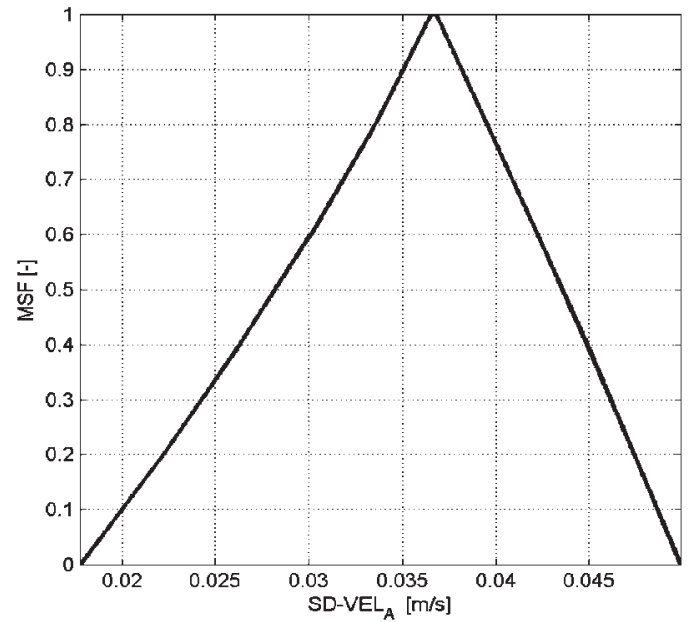

Fig. 8 Fuzzy standard deviation of the vertical velocity of point $A$

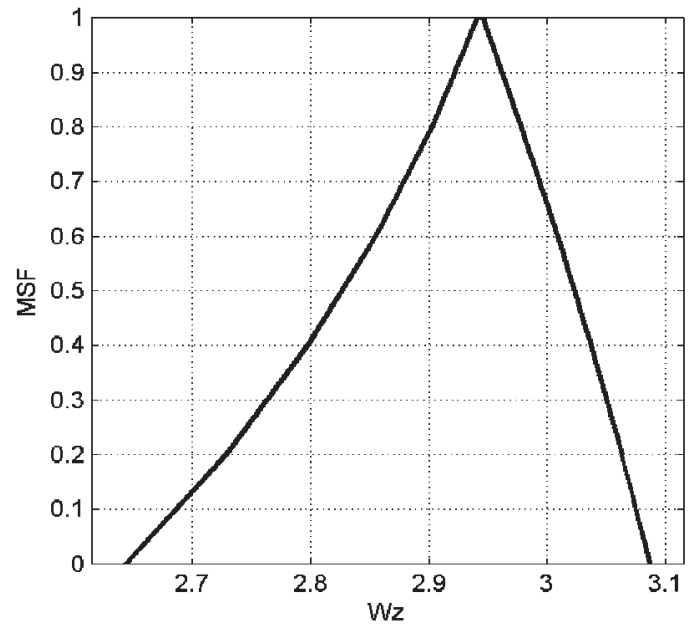

Fig. 10 Fuzzy mark of the ride quality of point $A$

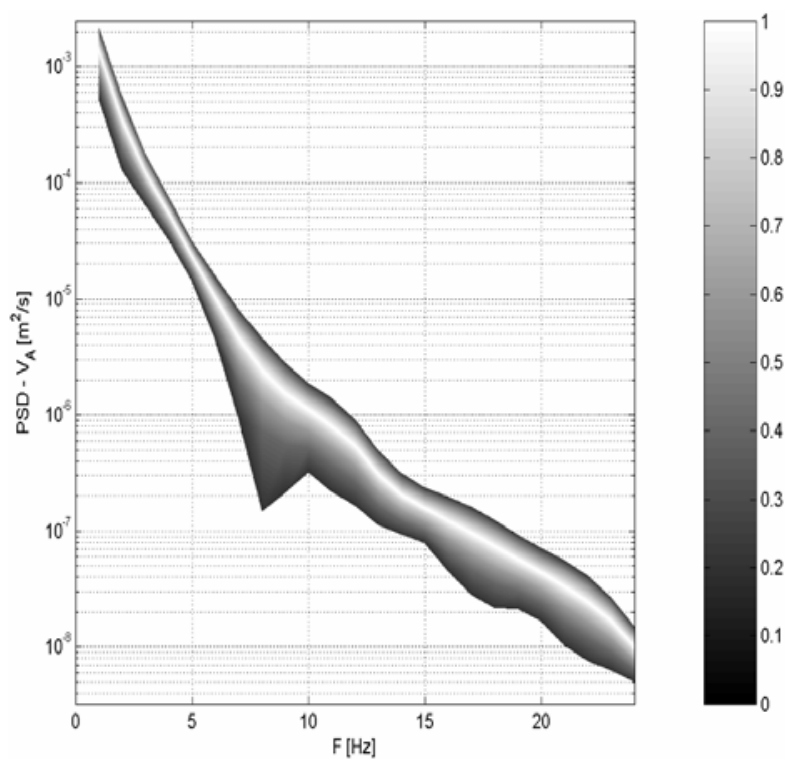

Fig. 12 Fuzzy PSD of the vertical velocity of point A 
the program CAR_FUZ.M was developed. The aim of the solution was to analyse the fuzzy standard deviation of the vertical displacement, velocity, acceleration and the mark of ride quality WA in point A which are presented in Figs. 7, 8, 9 and 10. Figs. 11, 12, and 13 present the fuzzy power spectral density of the vertical vibration in point $\mathrm{A}$.

\section{Conclusion}

The paper discusses the possibility of fuzzy arithmetic application in stochastic structural analysis. The use of fuzzy arithmetic provides a new possibility of the appraisal of machineries quality. Due to this numerical approach we can more authentically analyse mechanical, technological, service and economic properties of investigated structures.

In this paper, we have investigated the possibilities of stochastic solution for a simple vehicle computational model with fuzzy structural parameters. We have evaluated power spectral density and standard deviation of the vertical displacement, velocity and acceleration in selected point of the carriage (See Fig. 4). The fuzzy technique enables to appreciate the results in a broader context.

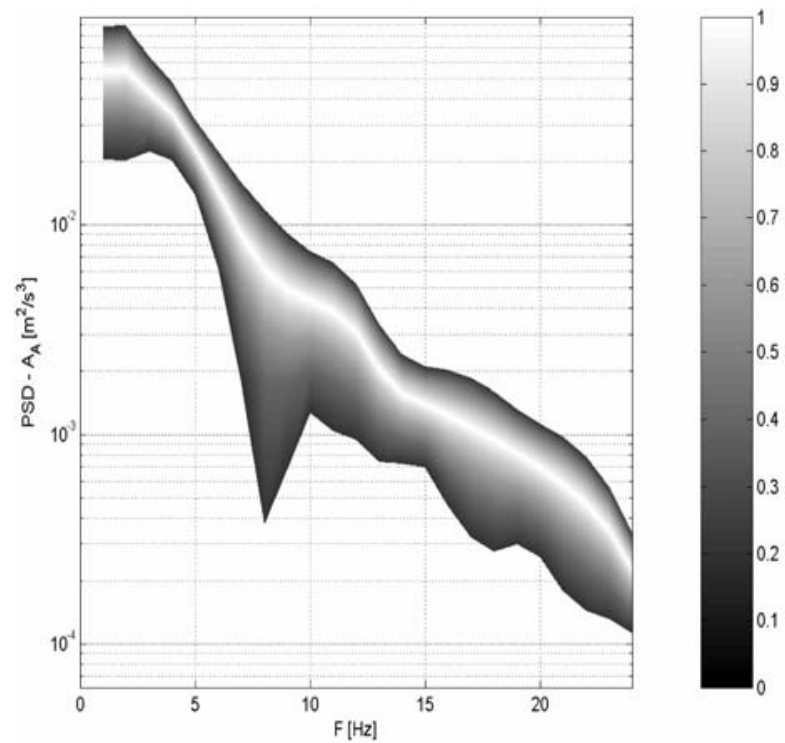

Fig. 13 Fuzzy PSD of the vertical acceleration of point $A$

This work has been supported by the VEGA grant No. $1 / 0280 / 03$.

\section{References}

[1] MOENS D., VANDEPITTE D.: Frequency response analysis of uncertain damped structures using the Fuzzy Finite Element Method, WCCM V, 7.-12. 7. 2002, Vienna, Austria.

[2] KULPA, Z., POWNUK, A., SKALNA, I.: Analysis of linear mechanical structures with uncertainties by means of interval methods, Computer Assisted Mechanics and Engineering Sciences, 1998, Vol. 5, Poland, pp. 443-477.

[3] KALINČÁK, D.: The power spectral densities of the measured track irregularities, Intern. Scient. Conf. „The transport of the 21st century", Warszawa, Poland, pp. 111-118

[4] FREIBAUER L.: Railway vehicles dynamics (in Czech), NADAS, Praha, 1991.

[5] MOORE R.E.: Methods and Applications of Interval Analysis, SIAM, Philadelphia, 1979.

[6] NEUMAIER A.: Interval Methods for Systems of Equations. Cambridge University Press, Cambridge, 1990.

[7] MAGLARAS G., EFSTRATIOS N., HAFTKA R. T., CUDNEY H. H.: Experimental comparison of probabilistic methods and fuzzy set based methods for designing under uncertainty, Uncertainty modelling in Vibration and Fuzzy Analysis of structural Systems, Series on Stability, Vibration and control of Systems, Series B: Vol. 10, world Scientific Publishing Company, Singapore, 1997, pp. 253-318.

[8] HANSS, M.: A nearly strict fuzzy arithmetic for solving problems with uncertainties, $19^{\text {th }}$ Int. Conf. of the North American Fuzzy Information Processing Society - NAFIPS '2000, pp. 439-443, Atlanta, USA, 2000.

[9] ZADEH, L. A.: Fuzzy sets, Information and Control, vol. 8, pp.338-353, 1965.

[10] ELISHAKOFF, I., DUAN, D.: Application of Mathematical Theory of Interval Analysis to Uncertain Vibrations, Proc. of NOISECON'94, Ft. Lauderdale, Florida, pp. 519-524, 1994.

[11] NOVÁK, V: Fuzzy sets and their applications (in Czech), SNTL Praha, 1990.

\section{APPENDIX}

The mass matrix $\boldsymbol{M}$ has seven non-zero entries along the main diagonal:

$$
\boldsymbol{M}=\left[\begin{array}{ccccccc}
n_{1} & 0 & 0 & 0 & 0 & 0 & 0 \\
0 & J z_{1} & 0 & 0 & 0 & 0 & 0 \\
0 & 0 & J x_{1} & 0 & 0 & 0 & 0 \\
0 & 0 & 0 & m_{2} & 0 & 0 & 0 \\
0 & 0 & 0 & 0 & J x_{2} & 0 & 0 \\
0 & 0 & 0 & 0 & 0 & m_{2} & 0 \\
0 & 0 & 0 & 0 & 0 & 0 & J x_{2}
\end{array}\right]
$$


The stiffness matrix $\boldsymbol{K}$ is

$$
\boldsymbol{K}=\left[\begin{array}{ccccccc}
4 \cdot k_{1} & 2 \cdot\left(a_{1}-a_{2}\right) \cdot k_{1} & 0 & -2 \cdot k_{1} & 0 & -2 \cdot k_{1} & 0 \\
2 \cdot\left(a_{1}-a_{2}\right) \cdot k_{1} & 2 \cdot k_{1} \cdot\left(a_{1}^{2}-a_{2}^{2}\right) & 0 & -2 \cdot k_{1} \cdot a_{1} & 0 & 2 \cdot k_{1} \cdot a_{1} & 0 \\
0 & 0 & 4 \cdot k_{1} \cdot c_{1}^{2} & 0 & -2 \cdot k_{1} \cdot c_{1}^{2} & 0 & -2 \cdot k_{1} \cdot c_{1}^{2} \\
-2 \cdot k_{1} & -2 \cdot k_{1} \cdot a_{1} & 0 & 2 \cdot k_{1}+2 \cdot k_{2} & 0 & 0 & 0 \\
0 & 0 & -2 \cdot k_{1} \cdot c_{1}^{2} & 0 & 2 \cdot k_{1} \cdot c_{1}^{2}+2 \cdot k_{2} \cdot c_{2}^{2} & 0 & 0 \\
-2 \cdot k_{1} & 2 \cdot k_{1} \cdot a_{1} & 0 & 0 & 0 & 2 \cdot k_{1}+2 \cdot k_{2} & 0 \\
0 & 0 & -2 \cdot k_{1} \cdot c_{1}^{2} & 0 & 0 & 0 & 2 \cdot k_{1} \cdot c_{1}^{2}+2 \cdot k_{2} \cdot c_{2}^{2}
\end{array}\right] .
$$

The damping matrix $\boldsymbol{B}$ is:

$$
\boldsymbol{B}=\left[\begin{array}{ccccccc}
4 \cdot b_{1} & 2 \cdot\left(a_{1}-a_{2}\right) \cdot b_{1} & 0 & -2 \cdot b_{1} & 0 & -2 \cdot b_{1} & 0 \\
2 \cdot\left(a_{1}-a_{2}\right) \cdot b_{1} & 2 \cdot b_{1} \cdot\left(a_{1}^{2}-a_{2}^{2}\right) & 0 & -2 \cdot b_{1} \cdot a_{1} & 0 & 2 \cdot b_{1} \cdot a_{1} & 0 \\
0 & 0 & 4 \cdot b_{1} \cdot c_{1}^{2} & 0 & -2 \cdot b_{1} \cdot c_{1}^{2} & 0 & -2 \cdot b_{1} \cdot c_{1}^{2} \\
-2 \cdot b_{1} & -2 \cdot b_{1} \cdot a_{1} & 0 & 2 \cdot b_{1}+2 \cdot b_{2} & 0 & 0 & 0 \\
0 & 0 & -2 \cdot b_{1} \cdot c_{1}^{2} & 0 & 2 \cdot b_{1} \cdot c_{1}^{2}+2 \cdot b_{2} \cdot c_{2}^{2} & 0 & 0 \\
-2 \cdot b_{1} & 2 \cdot b_{1} \cdot a_{1} & 0 & 0 & 0 & 2 \cdot b_{1}+2 \cdot b_{2} & 0 \\
0 & 0 & -2 \cdot b_{1} \cdot c_{1}^{2} & 0 & 0 & 0 & 2 \cdot b_{1} \cdot c_{1}^{2}+2 \cdot b_{2} \cdot c_{2}^{2}
\end{array}\right] .
$$

and the left side matrices are as follows

$$
\boldsymbol{T}_{k}=\left[\begin{array}{cccc}
0 & 0 & 0 & 0 \\
0 & 0 & 0 & 0 \\
0 & 0 & 0 & 0 \\
k_{2} & k_{2} & 0 & 0 \\
k_{2} \cdot c_{2} & -k_{2} \cdot c_{2} & 0 & 0 \\
0 & 0 & k_{2} & k_{2} \\
0 & 0 & k_{2} \cdot c_{2} & -k_{2} \cdot c_{2}
\end{array}\right] \quad \boldsymbol{T}_{b}=\left[\begin{array}{cccc}
0 & 0 & 0 & 0 \\
0 & 0 & 0 & 0 \\
0 & 0 & 0 & 0 \\
b_{2} & b_{2} & 0 & 0 \\
b_{2} \cdot c_{2} & -b_{2} \cdot c_{2} & 0 & 0 \\
0 & 0 & b_{2} & b_{2} \\
0 & 0 & b_{2} \cdot c_{2} & -b_{2} \cdot c_{2}
\end{array}\right]
$$

